\title{
Network loss reduction and voltage improvement by optimal placement and sizing of distributed generators with active and reactive power injection using fine-tuned PSO
}

\author{
Eshan Karunarathne $^{1}$, Jagadeesh Pasupuleti ${ }^{2}$, Janaka Ekanayake ${ }^{3}$, Dilini Almeida ${ }^{4}$ \\ ${ }^{1,2,4}$ Institute of Sustainable Energy (ISE), Universiti Tenaga Nasional (UNITEN), Malaysia \\ ${ }^{3}$ Department of of Electrical Engineering, University of Peradeniya, Sri lanka
}

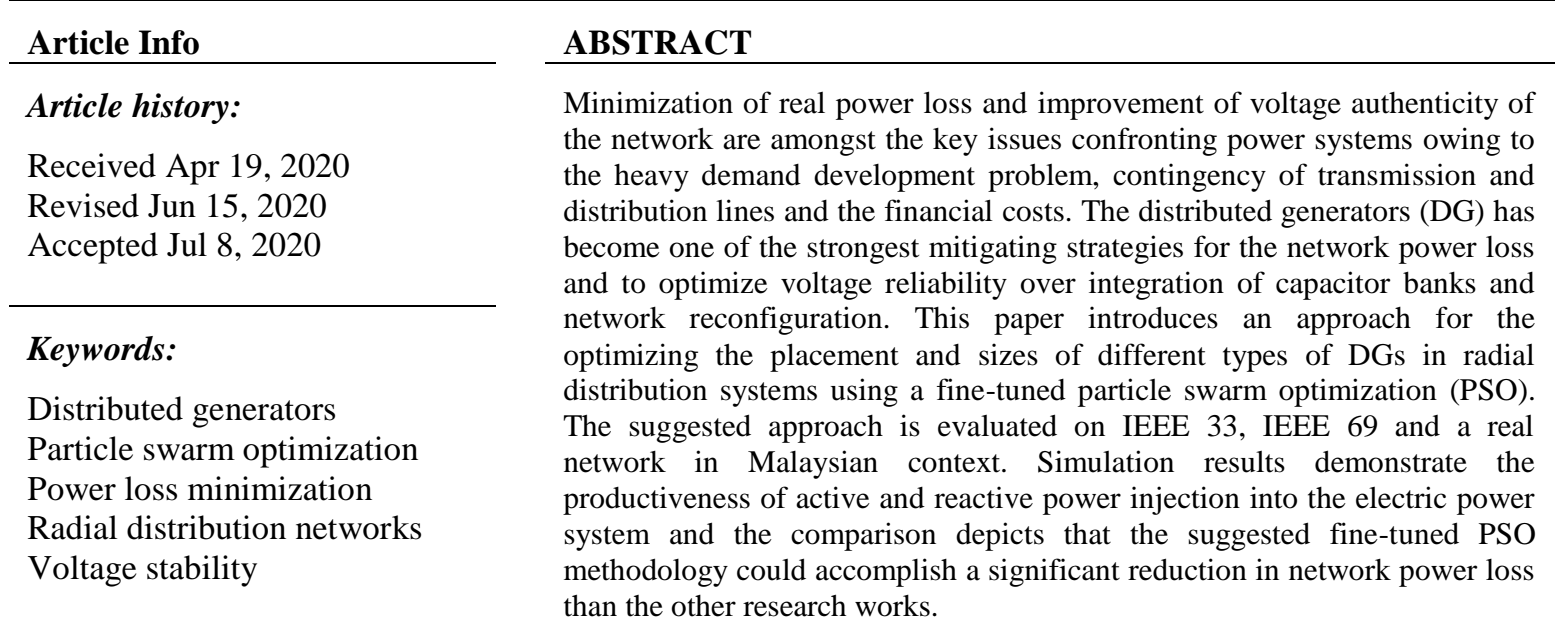

This is an open access article under the CC BY-SA license.

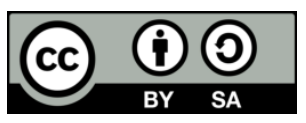

Corresponding Author:

Eshan Karunarathne

Institute of Sustainable Energy

University Tenaga Nasional (UNITEN)

Jalan IKRAM-UNITEN, 43000, Kajang, Selangor, Malaysia

Email: eshkaru16@gmail.com

\section{INTRODUCTION}

In today's world, the electrical power systems are confronting various technical issues, as consequences to the increased load growth of the last mile networks. These issues will further lead the networks to larger power losses, voltage drops, load imbalances and stability problems. Therefore, DGs have come up as a viable way of relieving such issues in a radial distribution network [1]. In [2], the DGs are defined as power generating sources, which are connected to the distribution systems, having a typical capacity of less than 50-100 MW. Small generators supplying the electric power required by the customers and these are scattered in a power system, is another definition of DGs [3, 4].

DG units generate power closer to the load centers, thus avoid the cost of energy transportation and reduce the power losses in transmission lines. Furthermore, the cost savings of the DG technologies are higher compared to the centralized generation station [5]. Normally, DGs are smaller in size and could be operated in stand-alone mode or in correlation with distribution network [6]. Hence, their impact on power system operation, control and stability depend on the DG size and the integrating location [7, 8]. However, non-optimized placement and sizing might increase the power losses as well as the violations in voltage statutory limits. Based on power injections, DGs have been classified in to four sections. Type I DGs only 
inject active power and type II DGs inject both active and reactive power. Type III DGs inject only reactive power, while type IV DGs inject active power and absorb reactive power.

At present, it has become very clear that the reactive power support is an essential requirement for the well-executed distribution networks. Integration of capacitors has been often used to compensate reactive power. Therefore, improvement in voltage profile within the acceptable limits minimizes power and energy losses. Many researchers have studied on optimal capacitor placement using different methods [9, 12]. However, the ability of injecting both active power and reactive power of DGs enhance the system performance than that of injecting only reactive power by power loss reduction.

In recent research work, many approaches have been undertaken to obtain a minimum network power loss by integration of DGs. These approaches can be mainly categorized as classical and artificial Intelligent algorithms [13]. A comparative study for DG allocation techniques based on active power and reactive power indices and voltage loss reduction has been addressed in [14]. In [15], a nonlinear programming (NLP) multi objective framework has been proposed for the perfect sitting and sizing of DG units. Minimizing the number of DGs and power losses together with maximizing the voltage stability margin are the objectives of this approach. An improved analytical method has been presented in [16] focusing on the identification of the best location of integration. But most of the analytical methods have been antiquated due to more time consumption and the less accuracy.

Genetic algorithms [17], Harmony search [18], particle swarm optimization (PSO) [19-21], and Tabu search [22] are some of the artificial intelligence techniques, that have been used to determine the optimal location and the size of the distributed generators. The main feature of the popularity of these techniques is the computational robustness. Reference [23] has presented a DG placement and sizing method considering reduction of system losses, voltage magnitude and stability enhancement. In [24], a new robust power flow method with whale optimization has been proposed for DG placement and sizing. Most of the research work related to optimal placement and sizing of DGs using PSO techniques disclose a low percentage of loss reduction. The usage of un-tuned PSO parameters is the principal cause for that poor loss reduction. Parameter selection could be identified as the key influence of the productivity and the performance.

In this paper, a fine-tuned particle swarm optimization approach and voltage stability index (VSI) have been used to determine the optimal size and location of the DGs to minimize the power losses while maintaining the voltage profile and stability margin. The algorithm parameters of PSO have been selected to obtain the minimum loss reduction. Most of the approaches presented so far have been utilized only type I DGs to the network to determine the optimal size and the location. In the current work, the capability of improving the power loss reduction and the voltage stability have been investigated by integrating both type I and type II DGs to the network systems. The effectiveness of the proposed approach is demonstrated on standard IEEE 33 bus, IEEE 69 bus and a real Malaysia 54 bus network system. The integration of type II DGs is suggested to improve the reduction of power loss and the voltage stability of the system.

\section{RESEARCH METHOD}

\subsection{Problem formulation}

\subsubsection{Objective function}

The main objective of allocating DGs in a distribution network is to get the maximum feasible benefits by enhancing the system's efficiency in terms of improving the power loss reduction. The problem could be mathematically formulated as an objective of minimizing the loss of real power.

$$
\text { Minimize } P_{L}=\sum_{i=1}^{N} P_{\text {loss }}=\sum_{i=1}^{N} I_{b r, i}^{2} \times R_{i} \text { for } i=1,2 \ldots \ldots . . N
$$

where $I_{b r, i}, R_{i}$ and $N$ are the $i^{\text {th }}$ branch current, the $i^{\text {th }}$ branch resistance and number of branches respectively.

\subsubsection{Constraints}

a) Voltage Constraints

Absolute value of the voltage magnitude at each node must be stationed within their allowable ranges in order to maintain the system's power quality. It is defined as below.

$$
\left|V_{\text {min }}\right| \leq V_{i} \leq\left|V_{\text {max }}\right| \text { for } i=1,2 \ldots \ldots . M
$$


b) DG capacity constraints

Total connected DG units' active and reactive power generation must be lower than the base system's active and reactive power loads. Furthermore, it should be lower than the DG's maximum generation capability. Mathematically, this constraint was defined as follows:

$$
\begin{aligned}
& P_{D G, \text { min }}<P_{D G}<P_{D G, \text { max }} \\
& Q_{D G, \text { min }}<Q_{D G}<Q_{D G, \text { max }}
\end{aligned}
$$

Assuming, $\alpha=\tan \left(\cos ^{-1}(P F)\right)$, where $P F$ is the power factor of DG unit, the generated reactive power can be expressed as:

$$
Q_{D G}<\alpha P_{D G}
$$

For type I DGs, $\alpha=0$ and for type II DGs, $0<\alpha<1$. The injected reactive power $Q_{i}$ at $i^{\text {th }}$ bus is:

$$
Q_{i}=\alpha P_{D G}-Q_{d}
$$

where $Q_{i}$ is the net reactive power demand at $i^{t h}$ bus. The thermal limit must not exceed its limits.

$$
S_{i} \leq S_{\max } \text { for } i=1,2 \ldots \ldots . . N
$$

\subsection{Particle swarm optimization (PSO)}

PSO algorithm is one of the evolutionary computation techniques that optimizes an objective function by iteratively attempting to improve a solution by giving considerations to predefined measure of quality. In this research work, PSO algorithm has been used to establish the optimal size of the DGs. An outline of the PSO with steps is given below. PSO algorithm is a population-based search algorithm oriented on the simulation of the social behavior of a birds' flock, introduced originally by Kennedy and Eberhart in 1995 [25]. The $n$ number of particles in the swarm represent the nominee solutions. Each particle is a real valued $m$ dimensional vector where $m$ is the number of parameters optimized. Consequently, every optimized parameter represents a dimension of the problem space.

- Step 1: Insert the data of the network for the power flow simulations and initialize parameters of PSO algorithm (i.e. number of iterations, number of particles, social coefficient $\left(C_{2}\right)$, cognitive coefficient $\left(C_{1}\right)$, minimum and maximum limits of inertia weight)

- Step 2: Construct randomly initialized swarm matrices for the position and velocity and run the base case power flow.

- Step 3: Use forward and backward sweep method to power flow simulations and compute the loss of active power (fitness function) using (1), the nodal voltages, and the flow of power in each line.

- Step 4: Test on the network constraints conmprising the voltages of the nodes, DG capacity and line power flows which is the thermal capacity as shown in (2) to (4) and (7). If all the constraints are satisfied, proceed to step 6; otherwise proceed to the next step.

- Step 5: Employ the penalty function method (PFM) for the DGs which are in breach of the constraints.

- Step 6: Identify the best personal experience (Pbest) of each particle and the best global experience (Gbest), out of every particle in the swarm.

- Step 7: Update each particle's position $\left(\mathrm{x}_{\mathrm{id}}{ }^{\mathrm{k}}\right)$ and velocity $\left(\mathrm{v}_{\mathrm{id}}{ }^{\mathrm{k}}\right)$ using (9) and (10). $\omega$ is the inertia constant and $\operatorname{rand}(\mathrm{)})$ is a randomly generated number $\in\left[\begin{array}{ll}0 & 1\end{array}\right]$. The equation for linearly increasing inertia constant in each iteration is shown in (8).

$$
\begin{aligned}
& \omega=\frac{\left(\omega_{\max }-\omega_{\min }\right)}{i t_{\max }} \times i t \\
& v_{i d}{ }^{k+1}=\omega v_{i d}{ }^{k}+C_{1} \operatorname{rand}() \times\left(P_{\text {best }}-x_{i d}{ }^{k}\right)+C_{2} \operatorname{rand}() \times\left(G_{\text {best }}-x_{i d}{ }^{k}\right) \\
& x_{i d}{ }^{k+1}=x_{i d}{ }^{k}+v_{i d}{ }^{k+1}
\end{aligned}
$$

\subsection{Voltage stability index}

The placement of the DGs is conducted by randomly choosing the positions from the VSI node array. The VSI node array is composed of the nodes, which have an index less than 0.9 as the nodes with 
lower values are more sensitive to collapse. The VSI is formed utilizing transferred active power and reactive power in a line as in (11).

$$
V S I=2\left|V_{r}\right|^{2}\left|V_{S}\right|^{2}-\left|V_{r}\right|^{4}-2\left|V_{r}\right|^{2}\left\{P_{i} R_{i}+Q_{i} X_{i}\right\}-\left|z_{i}\right|^{2}\left\{P_{i}^{2}+Q_{i}{ }^{2}\right\}
$$

where, $V_{r}, V_{s}, P_{i}, Q_{i}, R_{i}, X_{i}$ and $\left|z_{i}\right|$ are receiving end voltage, sending end voltage, active power of the load at $i^{\text {th }}$ bus, reactive power of the load at $i^{\text {th }}$ bus, resistive component of the $i^{\text {th }}$ line, reactive component of the $i^{\text {th }}$ line and impedance of the $i^{\text {th }}$ line respectively.

\subsection{Methodology}

The fine-tuned PSO technique for standard IEEE 33 bus, IEEE 69 bus and a real Malaysia 54 bus networks were implemented and simulated on MATLAB $^{\mathrm{TM}}$ simulation platform. The Malaysia 54 bus network is shown in Figure 1. Initially, Type I DGs were integrated and increased up to three number of DGs and recorded the results. Then Type II DGs with a PF of 0.9 were integrated to all the networks and followed the same procedure. The perfect solution for the placement and sizing in every network were obtained by performing PSO algorithm with the population size of 30.

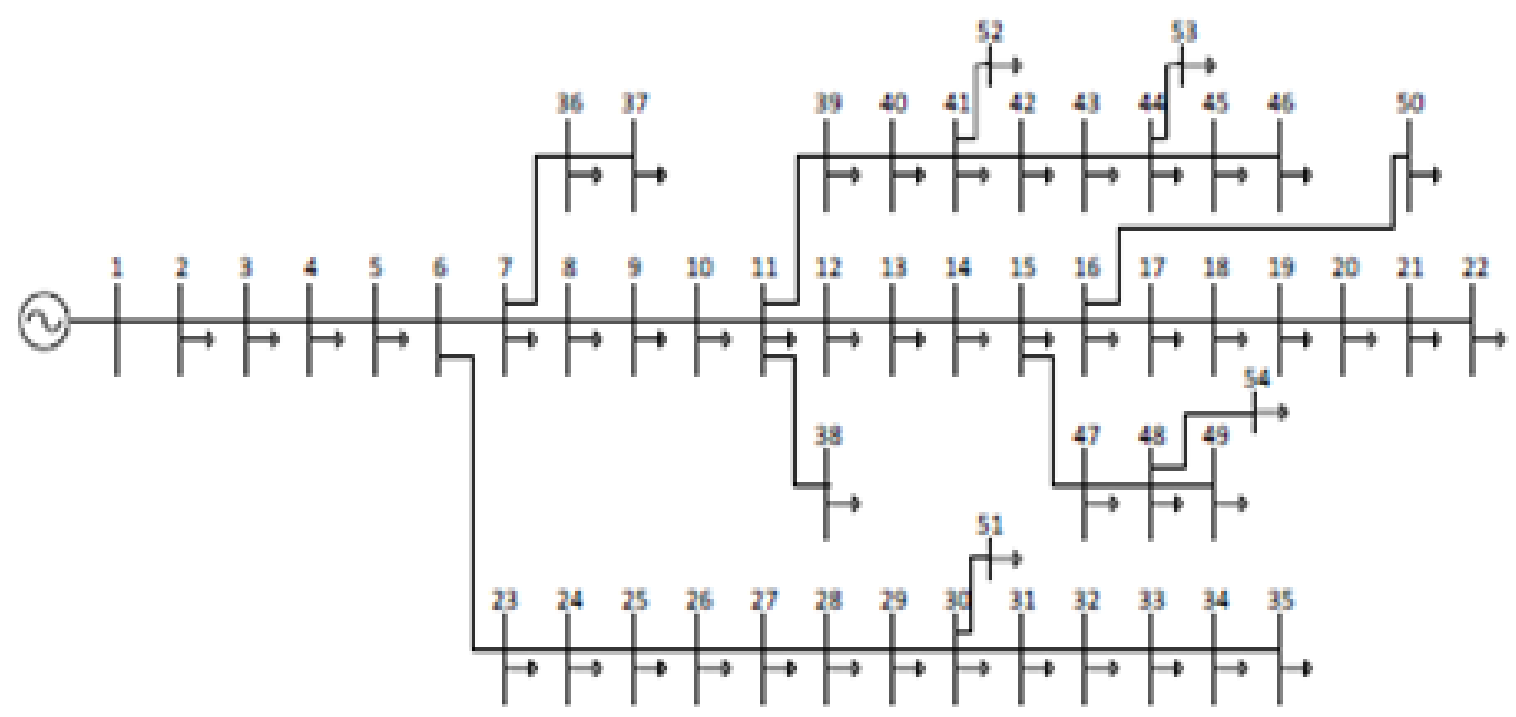

Figure 1. Malaysia 54 bus network

\section{RESULTS AND DISCUSSION}

The implemented routines described under methodology section were simulated and the optimal locations and sizes of DGs, voltage profiles, real power loss data were obtained. Figure 2(a), Figure 2(c) and Figure 2(e) present the voltage profiles after type I DG integration for IEEE 33 bus, IEEE 69 bus and Malaysia 54 bus networks respectively considering the unity power factor DGs. Figure 2(b), Figure 2(d) and Figure 2(f) depict the voltage profiles after type II DG integration for IEEE 33 bus, IEEE 69 bus and Malaysia 54 bus networks respectively and the power factor of every DG is defined as 0.9. In each graph under Figure 2, the base case without DGs, one DG, two DGs and three DGs were represented by blue, green, red and pink colour lines respectively. The statutory voltage limits of 1.05 pu (upper limit-red) and $0.95 \mathrm{pu}$ (lower limit-purple) were marked in dashed lines for clear illustration of the voltage profile. Figure 3 shows the active and reactive power losses for every network described under methodology section. In addition, convergence of the PSO algorithm is also acquired for the accuracy of the algorithm. Figure 4 shows the voltage profiles of three DG integrations, obtained for every type of DGs. 0.9 lagging and 0.9 leading power factors are used for type II and type IV DGs respectively. The results for optimal siting and sizing, power loss and power loss reduction percentage for each network were described in Table 1. 


\subsection{IEEE 33 bus system}

With a total load of $3.72 \mathrm{MW}$ and 2.30 Mvar, the IEEE 33 bus system is a radial distribution network. The overall active power loss in the base case system is $210.07 \mathrm{~kW}$, whereas total reactive power loss is 142.337 kvar. By examining the Figure 2(a), it was observed that, the base system has violated the lower statutory voltage limit at two intervals of the network. The voltage profiles after adding one, two and three DGs with unity PF show a growth in nodal voltage levels of base system and they lie inside the allowable boundaries except in one DG scenario. The single DG placement has yielded a network power loss reduction of $51.37 \%$, and it has increased to $65.29 \%$ after the placement of three DGs. However, the DGs with $0.9 \mathrm{PF}$ have reinforced the all voltage profiles higher than the lower statutory limit and there is an improvement in voltage profile compared to the DG integration with a unity power factor. It could be seen as shown in Figure 2(b). The maximum power loss reduction achieved by three DGs, having a 0.9 PF is $89.54 \%$ and it was $68.09 \%$ for single DG and $83.69 \%$ for two DGs. The DG sizes were varied from 0.7 MVA to 3 MVA for both type of DGs.

\subsection{IEEE 69 bus system}

The IEEE 69 bus system has connected to a total active load of $3.791 \mathrm{MW}$ and a reactive load of 2.694 Mvar. The active power loss and the reactive power loss without integrating DGs are $238.14 \mathrm{~kW}$ and 106.76 kvar respectively. By reviewing Figure 2(c), the single DG with unity PF has contributed a loss reduction of $65.35 \%$. Similarly, $69.07 \%$ and $69.72 \%$ are the loss reductions achieved by two and three DGs respectively. As shown Figure 2(d), it was revealed that a considerable voltage improvement for the segment after 50th bus was achieved by injecting reactive power in one, two and three DG scenarios. The power loss reduction for single DG with $0.9 \mathrm{PF}$ is $88.50 \%$ and $94.01 \%$ for two DGs with the same PF. Maximum loss reduction percentage was recorded with type II three DGs and it is $94.95 \%$. The optimal DG sizes were varied from 0.5 MVA to 4 MVA for both type of DGs.

\subsection{Malaysia 54 bus system}

The Malaysia 54 bus system is also a radial distribution network with a total active load of 4.595 MW and reactive load of 2.298 Mvar. The active and reactive power losses are $338.46 \mathrm{~kW}$ and $242.28 \mathrm{kvar}$ respectively. The system has violated the lower voltage limit in three sections. As expected, the violated voltage nodes have risen up their voltage magnitude by injecting type I DGs to the network system. It has achieved $72.26 \%$ from one DG, $78.0 \%$ from two DGs and $79.64 \%$ from three DGs. The improved variations in nodal voltages compared to the base system could be seen in Figure 2(e).

The Figure 2(f) shows how the nodal voltages in Malaysia network are deviated using both active and reactive power. It has significantly improved than that of injecting only active power and could be clearly observed from the graphs. The loss reduction has advanced up to $86.53 \%$ by adding single DG with $0.9 \mathrm{PF}$ and it was an increment in performance than three DGs with unity PF. After placing of DGs at perfect locations and sizes given by PSO algorithm, the network has attained a maximum power loss reduction of $96.25 \%$ by type II DGs. The active and reactive power losses in all the networks are shown in Figure 3 . As presumed, it demonstrates the reduction of power losses with the number of DGs connected as well as the type of the DG. Type II DGs (with 0.9 PF) have exhibited the maximum power loss reduction.

Figure 4 shows the gained loss reduction of type II DGs compared to the type I DGs and it has increased between $15 \%$ and $25 \%$. The variation of nodal voltages in IEEE 33 bus network for every type of DGs were shown in Figure 5. The least growth in voltage could be seen by type III DGs, which injects only reactive power. The next enhancement in nodal voltage was indicated by type IV DGs and it injects active power and absorbs reactive power. A moderate increment compared to the base system was displayed by type I DGs. They only inject active power. Type II DGs have achieved the best gain in nodal voltages by injecting both active and reactive power to the base system. Number of DGs were retained at three for all the cases described in Figure 5 and the leading and lagging PFs were fixed at 0.9. Table 2 shows the comparison of the results with other studies undertaken with unity PF and 0.866 lagging PF for IEEE 33 bus system. It is observed that the total loss reduction in proposed fine-tuned PSO technique is higher than the other methods. The percentage reduction in total losses are $65.29 \%$ and $92.09 \%$ for the DG penetrations with unity PF and 0.866 lagging PF respectively. 


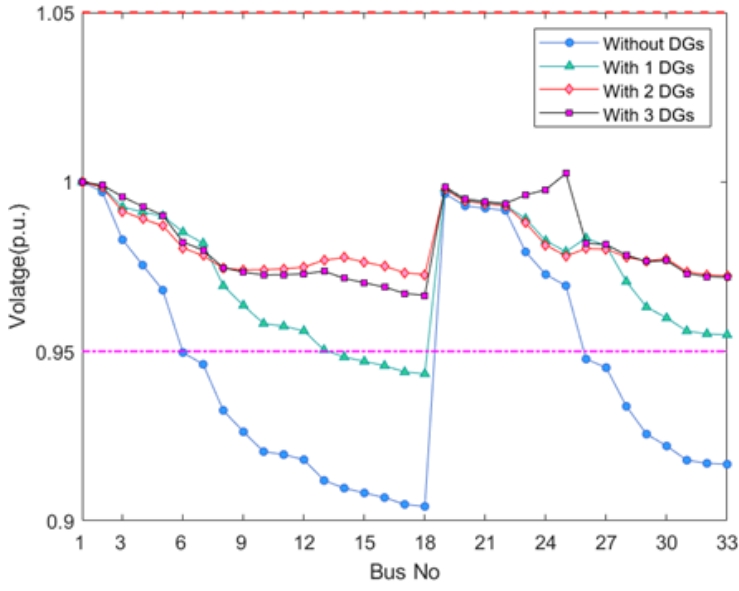

(a)

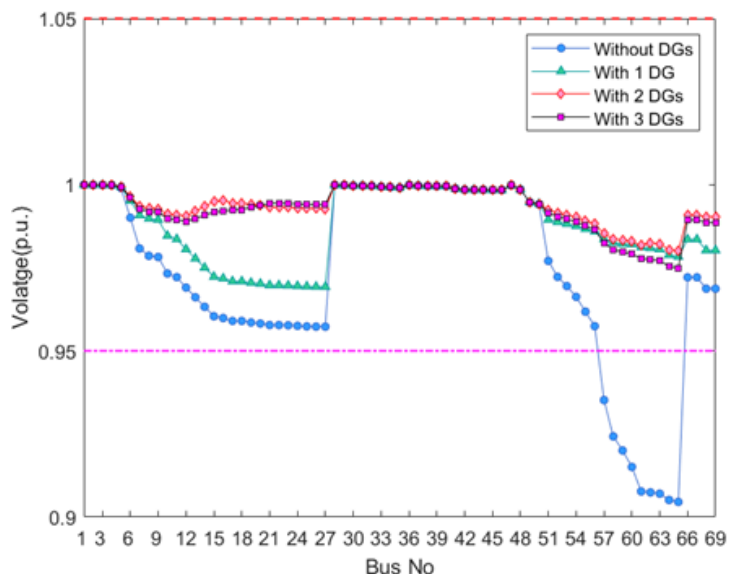

(c)

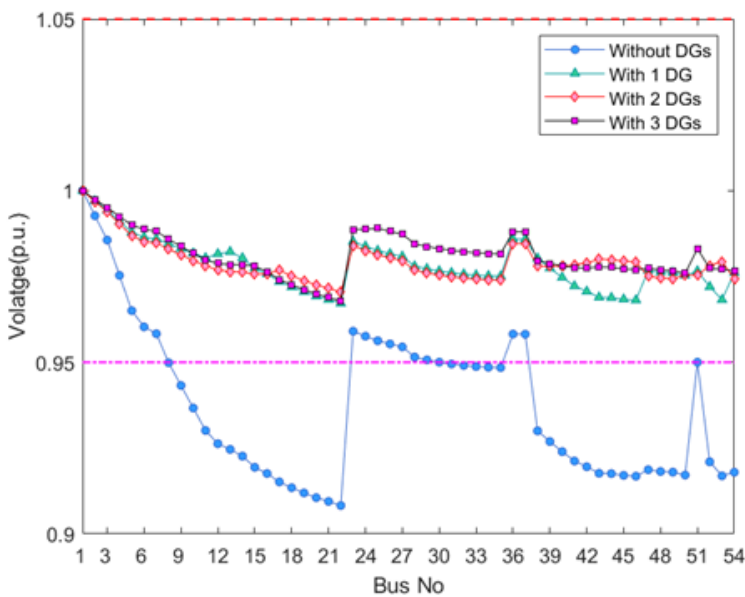

(e)

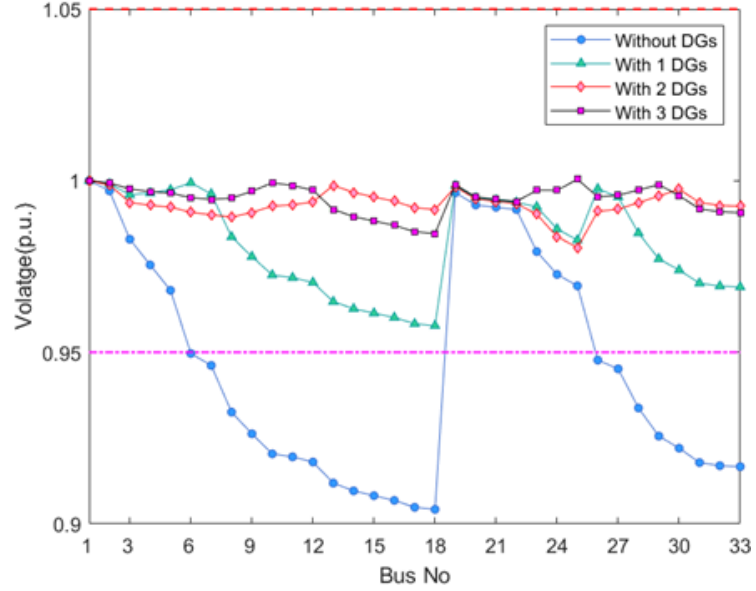

(b)

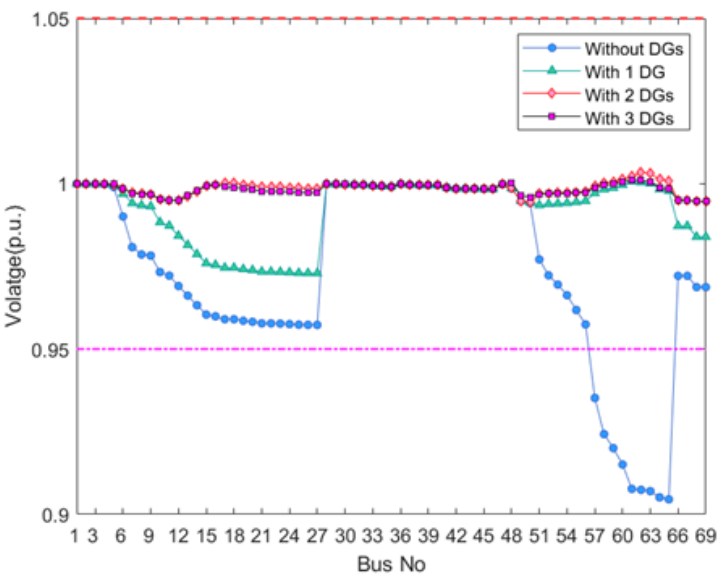

(d)

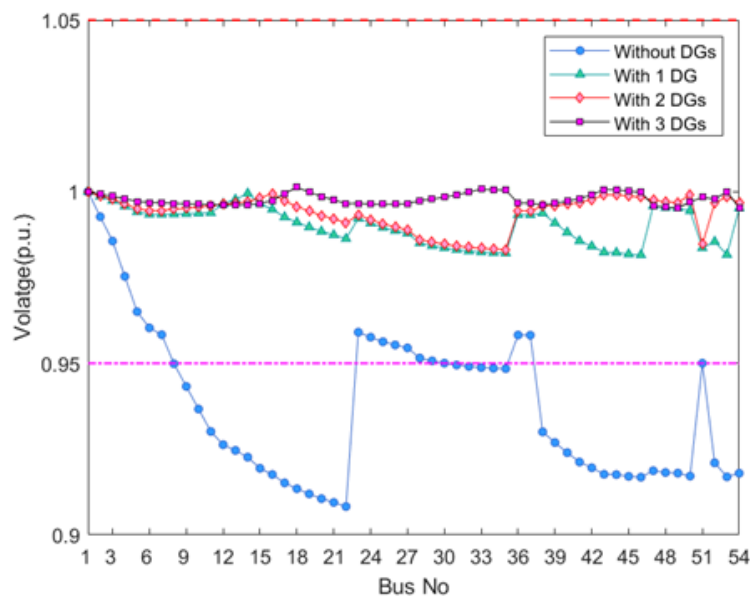

(f)

Figure 2. Variation of voltage profiles, (a) IEEE 33 bus (type I DG), (b) IEEE 33 bus (type II DG), (c) IEEE 69 bus (type I DG), (d) IEEE 69 bus (type II DG), (e) Malaysia 54 bus (type I DG), (f) Malaysia 54 bus (type II DG) 


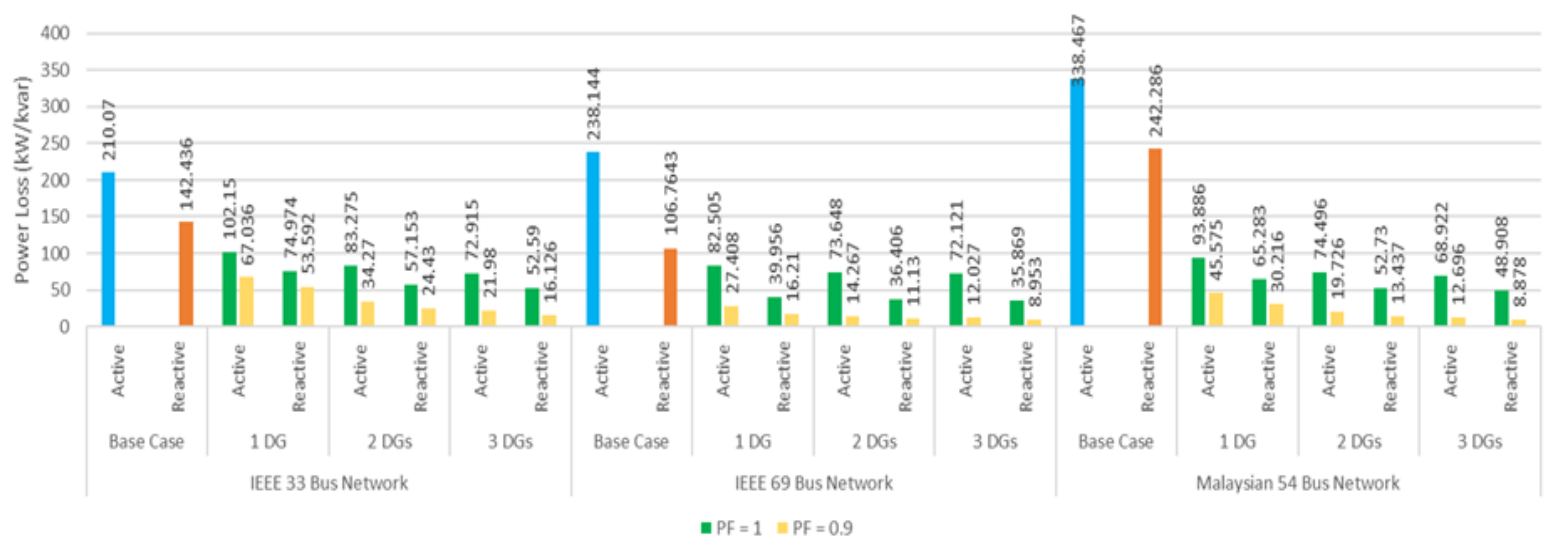

Figure 3. Active and reactive power losses of all networks

Table 1. Simulation results for test networks

\begin{tabular}{|c|c|c|c|c|c|c|c|c|c|c|}
\hline Network & $\begin{array}{c}\text { Power } \\
\text { Factor } \\
\text { (PF) }\end{array}$ & $\begin{array}{c}1^{\text {st }} \\
\text { DG } \\
\text { Node }\end{array}$ & $\begin{array}{l}1^{\text {st }} \mathrm{DG} \\
\text { Size } \\
(\mathrm{MW})\end{array}$ & $\begin{array}{c}2^{\text {nd }} \\
\text { DG } \\
\text { Node }\end{array}$ & $\begin{array}{l}2^{\text {nd }} \text { DG } \\
\text { Size } \\
(\mathrm{MW})\end{array}$ & $\begin{array}{c}3^{\text {rd }} \\
\text { DG } \\
\text { Node }\end{array}$ & $\begin{array}{c}3^{\text {rd }} \mathrm{DG} \\
\text { Size } \\
(\mathrm{MW})\end{array}$ & $\begin{array}{c}\text { Active } \\
\text { Power } \\
\text { Loss }(\mathrm{kW})\end{array}$ & $\begin{array}{c}\text { Reactive } \\
\text { Power } \\
\text { Loss(kVar) }\end{array}$ & $\begin{array}{c}\text { Loss } \\
\text { Reduction } \\
(\%)\end{array}$ \\
\hline \multirow{4}{*}{$\begin{array}{l}\text { IEEE } 33 \text { Bus } \\
\text { System }\end{array}$} & Base & - & - & - & - & - & - & 210.070 & 143.437 & - \\
\hline & \multirow[t]{3}{*}{1} & 30 & 1.243 & 12 & 0.815 & - & - & 83.275 & 57.153 & 60.36 \\
\hline & & 16 & 0.700 & 25 & 1.492 & 30 & 1.158 & 72.915 & 52.590 & 65.29 \\
\hline & & 6 & 2.920 & - & - & - & - & 67.036 & 53.592 & 68.09 \\
\hline \multirow{5}{*}{$\begin{array}{l}\text { IEEE } 69 \text { Bus } \\
\text { System }\end{array}$} & \multirow[t]{2}{*}{ Base } & - & - & - & - & - & - & 238.144 & 106.464 & - \\
\hline & & 61 & 1.999 & - & - & - & - & 82.505 & 39.956 & 65.35 \\
\hline & \multirow[t]{2}{*}{1} & 62 & 1.909 & 16 & 0.710 & - & - & 73.648 & 36.406 & 69.07 \\
\hline & & 3 & 3.941 & 61 & 1.878 & 21 & 0.556 & 72.121 & 35.869 & 69.72 \\
\hline & 0.9 & 61 & 2.192 & - & - & - & - & 27.408 & 16.210 & 88.50 \\
\hline \multirow{5}{*}{$\begin{array}{l}\text { Malaysia } 54 \text { Bus } \\
\text { System }\end{array}$} & \multirow[t]{2}{*}{1} & 43 & 1.885 & 17 & 2.138 & - & - & 74.496 & 52.738 & 78.00 \\
\hline & & 15 & 2.330 & 25 & 1.010 & 43 & 1.329 & 68.922 & 48.908 & 79.64 \\
\hline & \multirow{3}{*}{0.9} & 14 & 4.099 & - & - & - & - & 45.575 & 30.216 & 86.53 \\
\hline & & 44 & 1.590 & 16 & 2.653 & - & - & 19.726 & 13.437 & 94.17 \\
\hline & & 18 & 2.001 & 33 & 0.556 & 43 & 1.554 & 12.696 & 8.878 & 96.25 \\
\hline
\end{tabular}

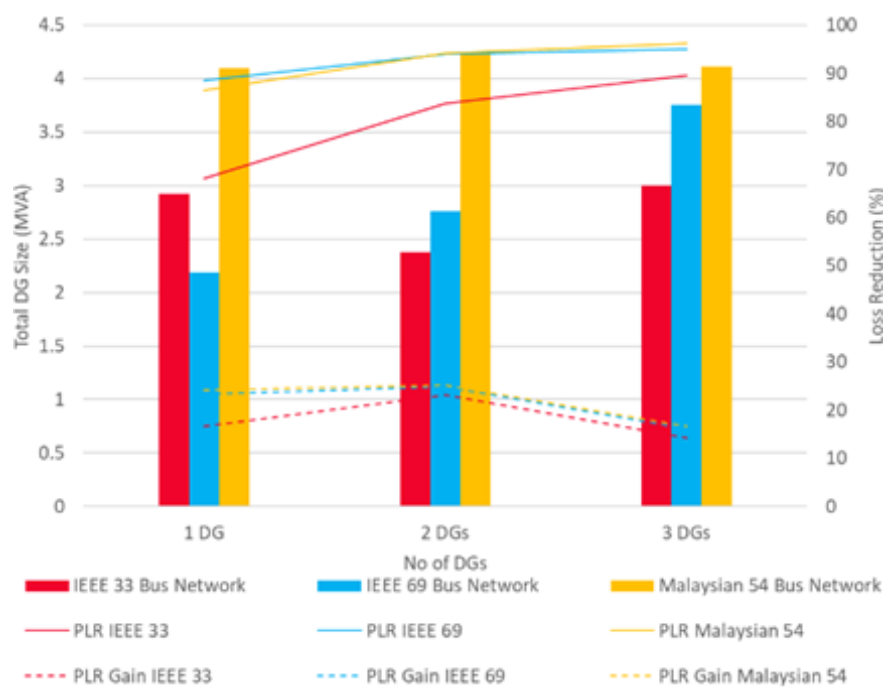

Figure 4. DG sizes and increment in loss reduction 


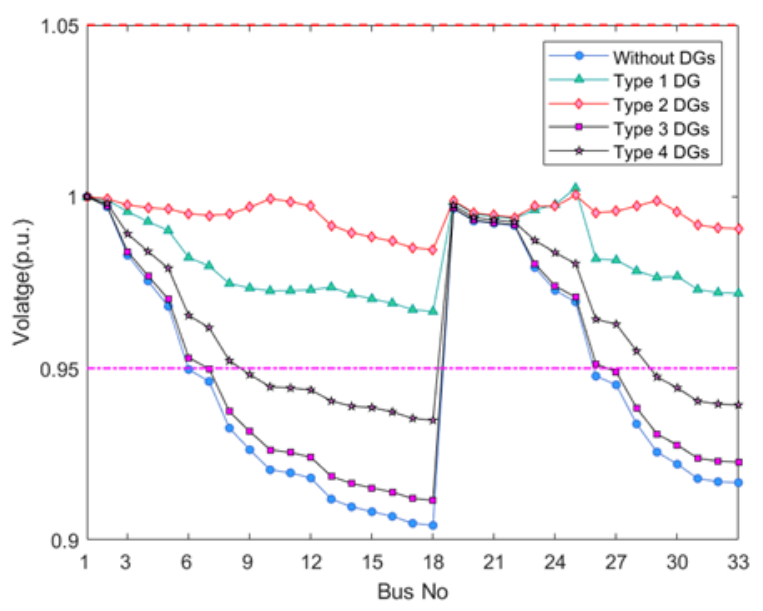

Figure 5. Voltage profiles of all types of DGs for IEEE 33 bus network

Table 2. Comparison of simulation results of IEEE 33 bus system with other research works

\begin{tabular}{|c|c|c|c|c|c|c|c|}
\hline \multirow{2}{*}{ Ref. } & \multirow{2}{*}{ Method } & \multicolumn{3}{|c|}{ Power factor $=1$} & \multicolumn{3}{|c|}{ Power factor $=0.866$} \\
\hline & & Location & Size(MVA) & $\mathrm{LR}(\%)$ & Location & Size(MVA) & $\mathrm{LR}(\%)$ \\
\hline & & 16 & 0.7000 & & 25 & 0.7965 & 92.09 \\
\hline \multirow{2}{*}{\multicolumn{2}{|c|}{ Proposed PSO Algorithm }} & 25 & 1.4922 & 65.29 & 30 & 1.3646 & \\
\hline & & 30 & 1.1589 & & 13 & 0.7382 & \\
\hline \multirow{4}{*}{ [26] } & & 11 & 1.5000 & & - & - & - \\
\hline & GA & 29 & 0.4228 & 49.61 & & & \\
\hline & & 30 & 1.0714 & & & & \\
\hline & & 13 & 0.9816 & & - & - & - \\
\hline \multirow[t]{3}{*}{ [26] } & PSO & 32 & 0.8297 & 50.06 & & & \\
\hline & & 8 & 1.1768 & & & & \\
\hline & & 32 & 1.2000 & & - & - & - \\
\hline \multirow[t]{3}{*}{ [26] } & GA/PSO & 16 & 0.8630 & 50.99 & & & \\
\hline & & 11 & 0.9250 & & & & \\
\hline & & 6 & 1.1124 & & 6 & 1.1976 & 87.33 \\
\hline \multirow[t]{3}{*}{ [27] } & SA & 18 & 0.4874 & 61.12 & 8 & 0.4778 & \\
\hline & & 30 & 0.8679 & & 10 & 0.9205 & \\
\hline & & 14 & 0.6521 & & 14 & 0.6798 & 82.06 \\
\hline \multirow[t]{3}{*}{ [28] } & BFOA & 18 & 0.1984 & 57.38 & 18 & 0.1302 & \\
\hline & & 32 & 1.0672 & & 32 & 1.1085 & \\
\hline & & 14 & 0.6247 & & 14 & 0.5176 & 81.64 \\
\hline \multirow[t]{2}{*}{ [29] } & IWO & 18 & 0.1049 & 57.47 & 18 & 0.1147 & \\
\hline & & 32 & 1.0560 & & 32 & 1.0842 & \\
\hline
\end{tabular}

\section{CONCLUSION}

This paper has presented a methodology of fine-tuned PSO technique to obtain the optimal location and sizing of different type of DGs in a radial distribution network. Type I DGs with unity PF and type II DGs with 0.9 PF were used for the integration to the system. The study presented, demonstrates how type II DGs are effective on enhancement in loss reduction and voltage stability of the network system. It was revealed that the proposed fine-tuned PSO performs better in comparison with other methods of optimization for the placement and sizing problems of distributed generators.

\section{ACKNOWLEDGEMENTS}

The authors would like to thank the Ministry of Education (MOE), Malaysia, for funding this research under a FRGS research grant (20180117FRGS).

\section{REFERENCES}

[1] P. P. Barker and R. W. De Mello, "Determining the impact of distributed generation on power systems. I. Radial distribution systems," 2000 Power Engineering Society Summer Meeting (Cat. No.00CH37134), Seattle, WA, vol. 3, pp. 1645-1656, 2000. doi: 10.1109/PESS.2000.868775. 
[2] N. Jenkins, J. B. Ekanayake, and G. Strbac, "Distributed generation," The Institution of Engineering and Technology, 2010.

[3] Soroudi, Alireza and M. Ehsan, "Multi-objective planning model for integration of distributed generations in deregulated power systems," Iranian Journal of Science Technology, vol. 34, no. 3, pp. 307-324, 2010.

[4] D. E. Olivares, C. A. Cañizares, and M. Kazerani, "A centralized optimal energy management system for microgrids," IEEE Power and Energy Society General Meeting, pp. 1-6, 2011.

[5] Willis, H. Lee, Scott, Walter G., "Distributed Power Generation: Planning and Evaluation," CRC Press, $1^{\text {st }}$ edition, 2000.

[6] K. D. Mistry and R. Roy, "Enhancement of loading capacity of distribution system through distributed generator placement considering techno-economic benefits with load growth," International Journal of Electrical Power and Energy Systems, vol. 54, pp. 505-515, 2014.

[7] R. A. Walling, R. Saint, R. C. Dugan, J. Burke, and L. A. Kojovic, "Summary of distributed resources impact on power delivery systems," IEEE Transactions on Power Delivery, vol. 23, no. 3, pp. 1636-1644, 2008.

[8] T. Ackermann and V. Knyazkin, "Interaction between distributed generation and the distribution network: Operation aspects," IEEE/PES Transmission and Distribution Conference and Exhibition, vol. 2, pp. 1357-1362, 2002. doi: 10.1109/TDC.2002.1177677.

[9] S. M. Kannan, P. Renuga, S. Kalyani, and E. Muthukumaran, "Optimal capacitor placement and sizing using fuzzy-DE and fuzzy-MAPSO methods," Applied Soft Computing Journal, vol. 11, no. 8, pp. 4997-5005, 2011.

[10] V. Tamilselvan, T. Jayabarathi, T. Raghunathan, and X. S. Yang, "Optimal capacitor placement in radial distribution systems using flower pollination algorithm," Alexandria Engineering Journal, vol. 57, no. 4, pp. 2775-2786, 2018.

[11] A. Elsheikh, Y. Helmy, Y. Abouelseoud, and A. Elsherif, "Optimal capacitor placement and sizing in radial electric powe r systems," Alexandria Engineering Journal, vol. 53, no. 4, pp. 809-816, 2014.

[12] A. Sadighmanesh, K. Zare, and M. Sabahi, "Distributed Generation unit and Capacitor Placement for Multi-objective Optimization," International Journal of Electrical and Computer Engineering (IJECE), vol. 2, no. 5, pp. 615-620, 2012.

[13] M. Pesaran H.A, P. D. Huy, and V. K. Ramachandaramurthy, "A review of the optimal allocation of distributed generation: Objectives, constraints, methods, and algorithms," Renewable and Sustainable Energy Reviews, vol. 75, pp. 293-312, 2017.

[14] J. J. Jamian, M. W. Mustafa, M. M. Aman, G. B. Jasmon, H. Mokhlis, and A. H. A. Bakar, "Comparative study on optimum DG placement for distribution network," Przeglad Elektrotechniczny, vol. 89, no. 3 A, pp. 199-205, 2013.

[15] M. Esmaili, "Placement of minimum distributed generation units observing power losses and voltage stability with network constraints," IET Generation, Transmission and Distribution, vol. 7, no. 8, pp. 813-821, 2013.

[16] D. Q. Hung and N. Mithulananthan, "Multiple distributed generator placement in primary distribution networks for loss reduction," IEEE Transactions on Industrial Electronics, vol. 60, no. 4, pp. 1700-1708, 2013.

[17] I. Pisica, C. Bulac, and M. Eremia, "Optimal distributed generation location and sizing using genetic algorithms," 2009 15th International Conference on Intelligent System Applications to Power Systems, pp. 1-6, 2009.

[18] P. Das, "Optimal allocation of distributed generation in a radial distribution system using loss sensitivity factor and harmony search algorithm," International Journal of Advanced Engineering Research and Science (IJAERS), vol. 2, no. 4, pp. 6-14, 2015.

[19] K. Bhumkittipich and W. Phuangpornpitak, "Optimal placement and sizing of distributed generation for power loss reduction using particle swarm optimization," Energy Procedia, vol. 34, pp. 307-317, 2013.

[20] J. J. Jamian, M. W. Mustafa, H. Mokhlis, and M. A. Baharudin, "A New Particle Swarm Optimization Technique in Optimizing Size of Distributed Generation," International Journal of Electrical and Computer Engineering (IJECE), vol. 2, no. 1, 2012.

[21] J. J. Jamian, M. W. Mustafa, H. Mokhlis, and M. A. Baharudin, "Implimentation of Evolutionary Particle Swarm Optimization in Distributed Generation Sizing," International Journal of Electrical and Computer Engineering (IJECE), vol. 2, no. 1, pp. 137-146, 2012.

[22] K. Nara, Y. Hayashi, K. Ikeda, and T. Ashizawa, "Application of tabu search to optimal placement of distributed generators," Proceedings of the IEEE Power Engineering Society Transmission and Distribution Conference, vol. 2, pp. 918-923, 2001.

[23] S. Essallah, A. Bouallegue and A. Khedher, "Optimal placement of PV-distributed generation units in radial distribution system based on sensitivity approaches," 2015 16th International Conference on Sciences and Techniques of Automatic Control and Computer Engineering (STA), Monastir, pp. 513-520, 2015.

[24] S. Ang and U. Leeton, "Optimal placement and size of distributed generation in radial distribution system using whale optimization algorithm," Suranaree Journal of Science and Technology, vol. 26, no. 1, pp. 1-12, 2019.

[25] J. Kennedy and R. Eberhart, "Particle swarm optimization," Proceedings of ICNN'95-International Conference on Neural Networks, Perth, WA, Australia, vol. 4, pp. 1942-1948, 1995.

[26] M. H. Moradi and M. Abedini, "A combination of genetic algorithm and particle swarm optimization for optimal DG location and sizing in distribution systems," International Journal of Electrical Power and Energy Systems, vol. 34, no. 1, pp. 66-74, 2012.

[27] S. K. Injeti and N. Prema Kumar, "A novel approach to identify optimal access point and capacity of multiple DGs in a small, medium and large scale radial distribution systems," International Journal of Electrical Power and Energy Systems, vol. 45, no. 1, pp. 142-151, 2013.

[28] I. A. Mohamed and M. Kowsalya, "Optimal size and siting of multiple distributed generators in distribution system using bacterial foraging optimization," Swarm and Evolutionary Computation, vol. 15, pp. 58-65, 2014.

[29] D. Rama Prabha and T. Jayabarathi, "Optimal placement and sizing of multiple distributed generating units in distribution networks by invasive weed optimization algorithm," Ain Shams Engineering Journal, vol. 7, no. 2, pp. 683-694, 2016.

Network loss reduction and voltage improvement by optimal placement and sizing of.. (Eshan Karunarathne) 


\section{BIOGRAPHIES OF AUTHORS}
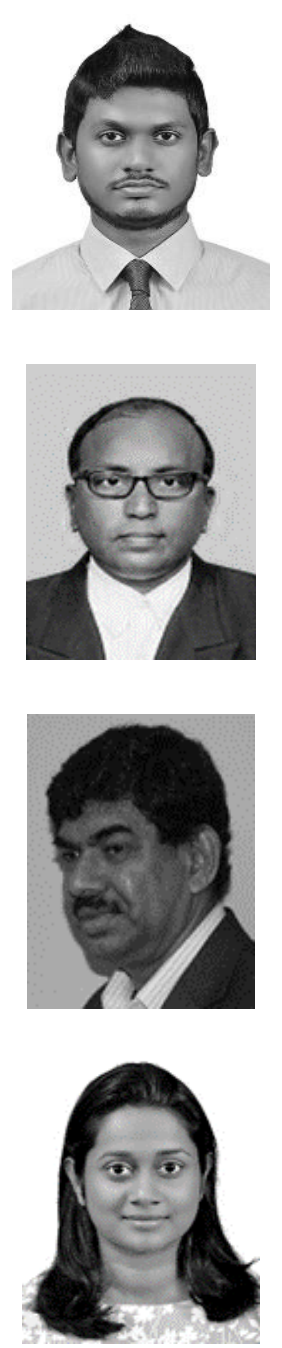

Eshan Karunarathne received the B.Sc.Eng. Degree in Electrical and Electronic Engineering from the University of Peradeniya, Sri Lanka, in 2017. He was a research assistant at Scool of Aerospace, Transport and Manufacturing, University of Cranfield, The United Kingdom. Currently he is a graduate research officer at institute of sustainable energy and pursuing his M.Sc. degree in electrical engineering at Institute of Sustainable Energy (ISE), Universiti Tenaga Nasional (The National Energy University), Malaysia. His main research interests include power system analysis, renewable energy integration and grid connected power electronic devices.

Dr. Jagadeesh Pasupuleti is the Head of Hybrid Renewable Energy Systems, Institute of Sustainable Energy, Universiti Tenaga Nasional, Malaysia. He is a Senior Member of IEEE (USA), Member of IET (UK), Chartered Engineer (UK), Professional Review Interviewer for CEng (UK), Member of EI (UK), Member of BEM (Malaysia) and Member of ISTE (India). He has 32 years of teaching, research and administrative experience. He has supervised 30 postgraduate students, published 100 papers and involved in 40 research and consultancy projects funded around $\$ 2$ million in renewable energy. His research interests include power system, hybrid renewable energy systems, smart grid, energy efficiency, electricity markets and demand side response.

Prof. Janaka B. Ekanayake received the B.Sc. degree in electrical engineering from the University of Peradeniya, Peradeniya, Sri Lanka, in 1990, and the Ph.D. degree in electrical engineering from the University of Manchester Institute of Science and Technology, Manchester, U.K., in 1995. He joined the University of Peradeniya, as a Lecturer, where he was promoted to a Professor of Electrical Engineering in 2003. In 2008, he joined the Cardiff School of Engineering, Cardiff, U.K. He is currently with the University of Peradeniya and Cardiff University, Cardiff. His current research interests include power electronic applications for power systems, renewable energy generation, and its integration and smart grid applications.

Dilini Almeida received the B.Sc.Eng. Degree in Electrical and Electronic Engineering from the University of Peradeniya, Sri Lanka, in 2017. Currently she is a graduate research officer at institute of sustainable energy and pursuing her M.Sc. degree in electrical engineering at Institute of Sustainable Energy (ISE), Universiti Tenaga Nasional (The National Energy University), Malaysia. Her main research interests include power system analysis and renewable energy integration. 